\title{
Reflexões Acerca Das Etapas De Identificação, Fissuração E Superação De Obstáculos De Aprendizagem No Ensino De Frações
}

\author{
Reflections About The Stages Of Identification, Fissuration And \\ Overcoming Learning Obstacles In The Teaching Of Fractions
}

\author{
Letícia Ribeiro Lyra * \\ Universidade Federal da Fronteira Sul - (UFFS) \\ Lucia Menoncini ** \\ Universidade Federal da Fronteira Sul - (UFFS) \\ Leandro Bordin *** \\ Universidade Federal da Fronteira Sul - (UFFS)
}

\begin{abstract}
Resumo
Neste artigo propomos analisar e discutir como o conceito de frações numéricas é apresentado no livro didático do $5^{\circ}$ ano do ensino fundamental. Para tal, recorremos às etapas de identificação, fissuração e superação dos obstáculos de aprendizagem, propostas por Astolfi (1999). As etapas são essenciais para que o estudante supere seus conhecimentos prévios inadequados conduzindo-os à automatização dos conhecimentos científicos. Destacamos que o ensino de frações é introduzido nos anos iniciais por professores de Pedagogia. Sabendo que este profissional precisa dar conta de múltiplos conhecimentos, para os quais muitas vezes se sente fragilizado, sinalizamos o reconhecimento das referidas etapas, com intuito de contribuir para o processo de ensino e de aprendizagem do conceito de frações.
\end{abstract}

Palavras-chave: Didática da Matemática; Obstáculos de Aprendizagem; Livro didático

\begin{abstract}
In this paper we aim to analyze and discuss how the concept of numerical fractions is presented in the textbook of the fifth grade of elementary school. In this way, we use the stages of identification, fissuration and overcoming obstacles of learning, proposed by Astolfi (1999). The steps are essential for the student to overcome their inadequate previous knowledge leading them to the automation of scientific knowledge. We emphasize that the

* Doutoranda do Programa de Pós-Graduação em Educação Científica e Tecnológica da Universidade Federal de Santa Catarina (PPGECT/UFSC). Professora Adjunta, Universidade Federal da Fronteira Sul (UFFS), Chapecó, SC, Brasil. E-mail: leticia.lyra@uffs.edu.br.

** Doutoranda do Programa de Pós-Graduação em Educação Científica e Tecnológica da Universidade Federal de Santa Catarina (PPGECT/UFSC). Professora Adjunta, Universidade Federal da Fronteira Sul (UFFS),

Chapecó, SC, Brasil. E-mail:E-mail:lucia.menoncini@uffs.edu.br, UFFS/UFSC, Bolsista do Programa UNIEDU Pós-Graduação ).

***Doutor pelo Programa de Pós-Graduação em Educação Científica e Tecnológica da Universidade Federal de Santa Catarina (PPGECT/UFSC). Professor Adjunto, Universidade Federal da Fronteira Sul (UFFS), Chapecó, SC, Brasil. E-mail: lbordin@uffs.edu.br.
\end{abstract}


teaching of fractions is introduced in the early years by teachers of Pedagogy. Knowing that this professional needs to carry out multiple knowledge, for which, he often feels fragile, we show the recognition of these steps, in order to contribute to the process of teaching and learning the concept of fractions.

KEYWORDS: Didactics of Mathematics; Learning Obstacles; Textbook

\section{Introdução}

Para a eficaz apropriação do conhecimento, a relação dialógica entre professor e aluno faz-se mister. Ambos assumem papéis e responsabilidades frente aos saberes científicos que serão explorados ao longo do processo formativo. O professor precisa conduzir didaticamente as diferentes situações e conteúdos, ao passo que o aluno deve se colocar na condição de partícipe do processo de construção do conhecimento. Este percurso formativo é, na maioria das vezes, mediado pelo livro didático. Muitos estudos, ao longo de vários tempos e contextos, dão conta de abordar tanto os aspectos didáticos, quanto a eficácia do livro didático no contexto escolar. Certamente, muito ainda há que ser feito na perspectiva de uma educação mais dinâmica e emancipadora.

Neste contexto, entendemos que é necessário discutir os obstáculos de aprendizagem envolvidos durante a construção do conhecimento científico. Este conceito foi introduzido pelo francês Jean-Pierre Astolfi e tem relação, em linhas gerais, com as concepções alternativas 1 que os estudantes possuem acerca do conhecimento e o trabalho do professor com vistas à apropriação de um novo modelo conceitual. Neste percurso, Astolfi $(1993 ; 1994 ; 1999)$ propõe identificar o obstáculo, fissurá-lo e trabalhar para a sua superação. A identificação (localização) do obstáculo corresponde à tomada de consciência (conscientização) por parte dos estudantes, ou seja: frente as suas concepções alternativas (implícitas ou explícitas) e ao seu próprio funcionamento intelectual é preciso saber que obstáculo se impõe ao avanço do conhecimento. A fissuração (confrontação) é produzida quando se manifesta uma desestabilização conceitual no estudante, a qual pode ocorrer com a oposição entre pontos de vista e a apresentação de diferentes situações/enfoques que estimulem o desenvolvimento intelectual: é o momento de conflito sociocognitivo. E por fim, a superação do obstáculo acontece na medida em que o estudante consegue elaborar um modelo explicativo alternativo que o permita esclarecer as incertezas geradas na etapa de fissuração criando, assim, condições para sua automatização em novas e diferentes situações.

1 Neste artigo os termos concepções, representações alternativas e ideias prévias, sistema de pensamento, sistema explicativo, modelo explicativo, serão utilizados como sinônimos. 
Como objeto de análise escolhemos, especificamente, o conteúdo de frações numéricas constante no livro didático "Coleção Porta Aberta: Matemática, Ensino Fundamental e Anos Iniciais" (CENTURIÓN; SCALA e RODRIGUES, 2014) que consta entre os livros avaliados pelo Programa Nacional do Livro Didático (BRASIL, 2015b).

A escolha do tópico de frações numéricas justifica-se devido a sua importância na inserção e consolidação do conceito de números racionais, o qual tem fortes implicações ao longo da vida escolar. Como destaca Lopes (2008), o tema contribui para que sejam introduzidas ideias importantes como aproximação, equivalência, arredondamento, proporção e probabilidade. No entanto, o autor questiona a forma como o assunto é abordado nos currículos escolares e defende uma nova postura frente as complexidades que envolvem o referido conceito. Para Lopes (2008, p. 7), “os obstáculos à aprendizagem são muitos e de várias naturezas". Iniciam com o fato de que a palavra fração tem relação com múltiplas ideias e conceitos (se constitui num conceito amplo composto por vários subconceitos), passam pela dificuldade de entender sua notação e, por consequência, de estabelecer comparações e realizar operações, além de repercutirem no pouco entendimento que se tem acerca de seu estatuto epistemológico.

Na mesma direção, Monteiro e Groenwald (2014, p. 110) apontam que o ensino e a aprendizagem do conceito de frações "é um processo complexo para os alunos e as dificuldades podem surgir quando estes transferem as propriedades do conjunto dos números naturais para as frações, não compreendendo as características particulares de cada conjunto numérico". Em seu estudo, os autores avaliaram sucessos e, principalmente, as fragilidades concernentes ao aprendizado de frações em relação a sete quesitos: conceito, tipos de frações, equivalência e simplificação, comparação entre frações, adição e subtração, multiplicação e divisão e resolução de problemas com frações. Neste sentido, argumentam que uma forma de melhorar o aprendizado é apresentar as frações em contextos variados e significativos, os quais propiciem aos estudantes as ferramentas necessárias para que consigam realizar com elas as mesmas atividades que desenvolvem com os números naturais.

Novaes e Venites (2015, p. 14) realizaram um estudo sobre o percurso histórico do conteúdo frações presente na "Revista em Ensino", no período entre 1951 a 1963 e observaram que se ensina da mesma maneira daquela época, sendo que a "a ênfase que ainda é dada no entendimento das frações como uma relação parte-todo/medida e foco nas operações". Bartz de Sá (2011) aponta que há uma repulsa dos estudantes por este conteúdo. Segundo a autora, uma das explicações dessa "aversão" seria a dificuldade de aprendizagem deste conteúdo pelos 
alunos, em especial, da maneira como é ensinado, como se fosse somente representado pela parte/todo, em vez de ensinar a equivalência e suas diferentes representações.

Neste sentido, verificamos que este conteúdo é considerado relevante de ser ensinado, tanto pelo que observamos nos documentos legais, quanto no que foi identificado por Oliveira (2007). Porém, uma questão fica em aberto: o professor pedagogo, com sua parca formação de conteúdos específicos, consegue trabalhar o conteúdo de fração de tal forma que promova a aprendizagem dos alunos? Ele estão preparados para identificar os obstáculos de aprendizagem que os alunos apresentam?

Alicerçados em tais conceitos, justificativas e indagações, a intenção deste estudo é avaliar se a forma como o conteúdo de frações numéricas é apresentado no livro didático (anteriormente mencionado) propicia condições de identificar, fissurar e superar obstáculos de aprendizagem. Neste percurso, faremos inserções acerca de atividades que o professor polivalente, licenciado em Pedagogia, pode utilizar na tentativa de favorecer a superação dos obstáculos didáticos, já que o foco deste trabalho são os anos iniciais do ensino fundamental.

Sendo assim, embora o assunto pareça estar localizado, no âmbito da tríade didática, na relação entre o aluno e o conhecimento, o terceiro elemento (o professor) permeará a discussão que ora nos propomos realizar. Mais que isso: o diálogo acontecerá entre o conhecimento ('transposto' num livro didático), o professor e seus recursos (muitos alicerçados no livro didático) e o aluno que precisa, de fato, apropriar-se de um conhecimento intelectualmente satisfatório, o qual sirva de ferramenta para seu bem viver.

\section{Trabalho Didático No Campo Do Ensino De Matemática}

A fim de mediar e criar condições para a profícua relação entre conhecimento, professor e aluno, a didática, há muito tempo ganha força como campo teórico. Ela está relacionada com $\mathrm{o}$ ato de ensinar e, portanto, deve fazer parte do trabalho escolar nos mais diferentes níveis. $\mathrm{O}$ fazer pedagógico consciente, com vistas ao objetivo da aprendizagem, deve ser perseguido por todos aqueles que se envolvem nos processos educativos.

Oliveira (1995) destaca como objetivos da didática: a reflexão sobre o papel sociopolítico da educação, da escola e do ensino; a compreensão do processo de ensino e suas múltiplas determinações; a instrumentalização teórica e prática do futuro professor para entender e resolver os problemas (im)postos pela prática pedagógica e o redimensionamento da prática pedagógica por meio da elaboração de propostas de ensino numa perspectiva crítica de 
educação. Para dar conta dessa complexidade, a didática tem seu corpo teórico alicerçado nas contribuições da Psicologia, da Filosofia e da Sociologia, que são áreas do conhecimento, que fundamentam as práticas pedagógicas. Sendo assim, se ocupa dos domínios psicológico (estratégias de apropriação do conhecimento), epistemológico (elaboração de conteúdos) e praxeológico (interações didáticas).

Especificamente no ensino de Matemática, D'Amore (2007) discorre que os primeiros estudos sobre Didática da Matemática foram desenvolvidos na França em meados da década de 1970 a partir dos trabalhos de Guy Brosseau. Como um dos pioneiros da Didática da Matemática, Brosseau (1996) desenvolveu uma teoria para compreender as relações que acontecem entre estudantes, professor e saber em sala de aula e, ao mesmo tempo, propôs situações que foram experimentadas e analisadas ao longo dos anos subsequentes. Brosseau (1996) considera que docentes e estudantes são atores indispensáveis da relação de ensino e aprendizagem, mas lança questionamentos sobre um terceiro elemento: o meio em que a situação (didática e a-didática) acontece.

Fechando o panorama sobre Didática da Matemática é importante salientar que Artigue (1996, p.196) discute o conceito de Engenharia Didática que segundo a autora é definido por um "esquema experimental baseado em realizações didáticas em sala de aula, ou seja, na concepção, realização, observação e análise de sequências de ensino”. A Engenharia Didática é, pois, uma metodologia de pesquisa e teoria educacional elaborada no início da década de 1980, para trabalhos de Educação Matemática. Foi assim chamada uma vez que representa uma forma de trabalho didático semelhante ao trabalho de um engenheiro que para realizar um projeto, se apoia nos conhecimentos científicos do seu domínio e aceita se submeter, da mesma forma, a um controle do tipo científico. Essa sequência planejada tem por objetivo obter informações para desvelar o fenômeno investigado.

\section{A Pedagogia E O Ensino De Matemática}

O curso de Pedagogia no Brasil é o responsável pela formação de professores para atuar nos anos iniciais e finais e deverá ser realizado em cursos de licenciatura plena, de nível superior, conforme previsto na LDB/96 (BRASIL, 1996) e nas Diretrizes Curriculares Nacionais para a Formação de Professores da Educação Básica (BRASIL, 2015a). Neste curso, "deverão preponderar os tempos dedicados à constituição de conhecimento sobre os objetos de ensino" (BRASIL, 2015a, p. 49), o que inclui conhecimentos na área de Linguagem, Ciências 
da Natureza, Matemática e Ciências Humanas. Ou seja, os professores polivalentes deverão estar habilitados a ensinar todos os conteúdos destas diferentes áreas de conhecimento. Especialmente, quanto ao conteúdo de Matemática no ensino fundamental, podemos analisar que os Parâmetros Curriculares Nacionais (PCN) (BRASIL, 1997) e Proposta Curricular de Santa Catarina (PCSC)(SANTA CATARINA, 2014) trazem orientações inovadoras.

Os PCN preveem que o ensino de matemática possibilite a

[...]formação de capacidades intelectuais, na estruturação do pensamento, na agilização do raciocínio dedutivo do aluno, na sua aplicação a problemas, situações da vida cotidiana e atividades do mundo do trabalho e no apoio à construção de conhecimentos em outras áreas curriculares." (BRASIL, 1997, p. 29).

A Proposta Curricular de Santa Catarina aponta que a aprendizagem dos conceitos matemáticos nos anos iniciais e finais do ensino fundamental contribui para formação integral dos estudantes sendo importante para a vida social, econômica e política destes. Segundo exposto no documento "o que caracteriza a Matemática é a conceituação de grandezas, formas, ordens e distribuições, assim como a operação e manipulação com tais conceitos" (SANTA CATARINA, 2014, p.160). Neste sentido, o professor que ensina nesta etapa da educação básica tem um papel relevante na construção de uma atitude positiva do estudante em relação aos conhecimentos matemáticos.

Porém, observa-se que são frequentes as dificuldades de aprendizagem dos estudantes em conhecimentos matemáticos. Entretanto, não se deve responsabilizar exclusivamente os professores pela pouca aprendizagem dos estudantes, considerando-se que estes, em sua maioria, tiveram uma formação deficitária, já que a disciplina de formação específica para ensino de matemática tem carga horária reduzida nos currículos de cursos de Pedagogia (OLIVEIRA, 2007; BEZERRA e BODEZAN, 2015), contrariando o que propõe as Diretrizes Nacionais de Formação de professores, conforme já exposto.

Considerando-se que nosso objeto de investigação é sobre o ensino de frações, Oliveira (2007, p.112) analisou em seu estudo com professores de Cursos Normais Superiores e de Pedagogia que o ensino deste conteúdo está atrelado ao estudo dos números, sendo "as frações entendidas como de real importância". O ensino de frações é abordado em dois documentos legais: nos Parâmetros Curriculares Nacionais (BRASIL, 1997) e na Base Nacional Comum Curricular (BRASIL, 2017). Os PCN preveem no $4^{\circ}$ e $5^{\circ}$ ano a escrita e leitura de números naturais e racionais (frações e decimais) e o ensino deve proporcionar experiências com diferentes significados e representações fracionárias. No Documento da BNCC (BRASIL, 2017), as orientações apontam a introdução do ensino de frações no $4^{\circ}$ ano e no $5^{\circ}$ ano o conhecimento 
números racionais devem se ampliados para os números racionais na forma decimal. Observase que existem diferentes modalidades de metodologias para o ensino deste conteúdo.

A Proposta Curricular de Santa Catarina (SANTA CATARINA, 2014, p. 158) não especifica o conteúdo de frações, mas propõe que "os assuntos tratados em cada componente curricular devem ter complexidade de acordo com os diferentes momentos do percurso formativo dos estudantes".

\section{O Livro Didático E O Percurso De Automatização Do Conhecimento Matemático}

No ensino de modo geral e em particular no ensino de Matemática, o livro didático é um instrumento para auxiliar no processo de ensino e de aprendizagem e desempenha seu papel à medida que orienta o trabalho docente em sala de aula, seja em relação aos objetivos a serem alcançados, seja em relação aos conteúdos fundamentais a serem abordados, ou mesmo, em relação às metodologias e às estratégias de ensino que poderão ser utilizadas (DANTE, 1996). Neste sentido o autor destaca algumas razões que justificam a importância do livro didático no processo de ensino e de aprendizagem:

\footnotetext{
- em geral, só a aula do professor não consegue fornecer todos os elementos necessários para a aprendizagem do aluno, uma parte deles como problemas, atividades e exercícios pode ser coberta recorrendo-se ao livro didático; - o professor tem muitos alunos, afazeres e atividades extracurriculares que o impedem de planejar e escrever textos, problemas interessantes e questões desafiadoras, sem ajuda do livro didático;

- a matemática é essencialmente sequencial, um assunto depende do outro, e o livro didático fornece uma ajuda útil para essa abordagem;

um livro didático correto e com enfoque adequado pode ajudar a suprir essa deficiência;

- muitas escolas são limitadas em recursos como bibliotecas, materiais pedagógicos, equipamento de duplicação, vídeos, computadores, de modo que o livro didático constitui o básico, senão o único recurso didático do professor; - a aprendizagem da matemática depende do domínio de conceitos e habilidades. O aluno pode melhorar esse domínio resolvendo os problemas, executando as atividades e os exercícios sugeridos pelo livro didático; - o livro didático de matemática é tão importante quanto um dicionário ou uma enciclopédia, pois ele contém definições, propriedades, tabelas e explicações, cujas referências são frequentemente feitas pelo professor (DANTE, 1996, p. $83)$.
}

De acordo com Dante (1996), o livro didático tem sido o principal, e por vezes, o único instrumento de apoio dos professores de Matemática.

A influência exercida pelo livro didático na prática docente é um fenômeno conhecido, chegando a impor a rotina de trabalho de muitos professores. Ao tempo que representa um instrumento eficaz, oferecendo ao professor o ponto de partida da caminhada rumo à 
aprendizagem e contribuindo para o desenvolvimento da autonomia do estudante, também pode ser entendido como algo pronto e acabado, cabendo ao professor apenas informar ao estudante a página e o conteúdo a ser estudado. Assim, a forma como o livro didático é utilizado em sala de aula pode se tornar um obstáculo para a aprendizagem.

Outro ponto relevante sobre o livro didático refere-se à apresentação dos conceitos matemáticos. A maneira como os conceitos são apresentados é fundamental para o processo de ensino e de aprendizagem. As informações e as situações contidas no livro didático, bem como a sua disposição podem potencializar o processo ou se transformar em obstáculo para a aprendizagem.

Focando neste segundo ponto, vamos analisar e discutir a maneira como o conceito de frações numéricas é apresentado nos livros didáticos de Matemática, percebendo se ela representa um obstáculo para a aprendizagem e neste caso, se apresenta possibilidades para sua superação. Segundo Astolfi (1994), os obstáculos não podem ser entendidos como fatores negativos à aprendizagem, pois se analisados adequadamente podem guiar as práticas docentes tornando-se objetivos a serem alcançados. Com base nas ideias de Astolfi (1999), buscamos sinalizar ao professor o caminho para o reconhecimento das etapas de identificação, de fissuração e de superação de obstáculos de aprendizagem, referentes ao conceito de frações.

Quanto às escolhas que fizemos referentes ao conceito, ao livro e às situações-problema, as duas primeiras já foram justificadas no início deste trabalho. Quanto às situações escolhidas, observamos a sequência didática contemplada no livro e selecionamos a primeira situaçãoproblema que correspondia a cada etapa proposta por Astolfi (1999).

A ideia de frações numéricas, ou simplesmente frações, geralmente é introduzida no $4^{\circ}$ ano do ensino fundamental, sendo retomada no $5^{\circ}$ ano e aprofundada no $6^{\circ}$. Nos anos seguintes o conceito é explorado e aplicado para resolver situações diversas.

No livro analisado, a ideia de fração é apresentada a partir da relação parte-todo, apresentando situações-problema que discutem sobre o 'todo' (ideia que corresponde a um número inteiro) e sobre as 'partes', estabelecendo possíveis relações entre eles. Se observarmos outras obras que versam sobre o conceito de frações, poderemos reconhecer similaridades em suas apresentações e desta forma, a discussão iniciada neste trabalho pode ser estendida para outras obras e contextos.

A situação-problema 1 (Figura 1) é também a primeira situação apresentada no livro didático, sendo o ponto de partida para a introdução do conceito de fração. 


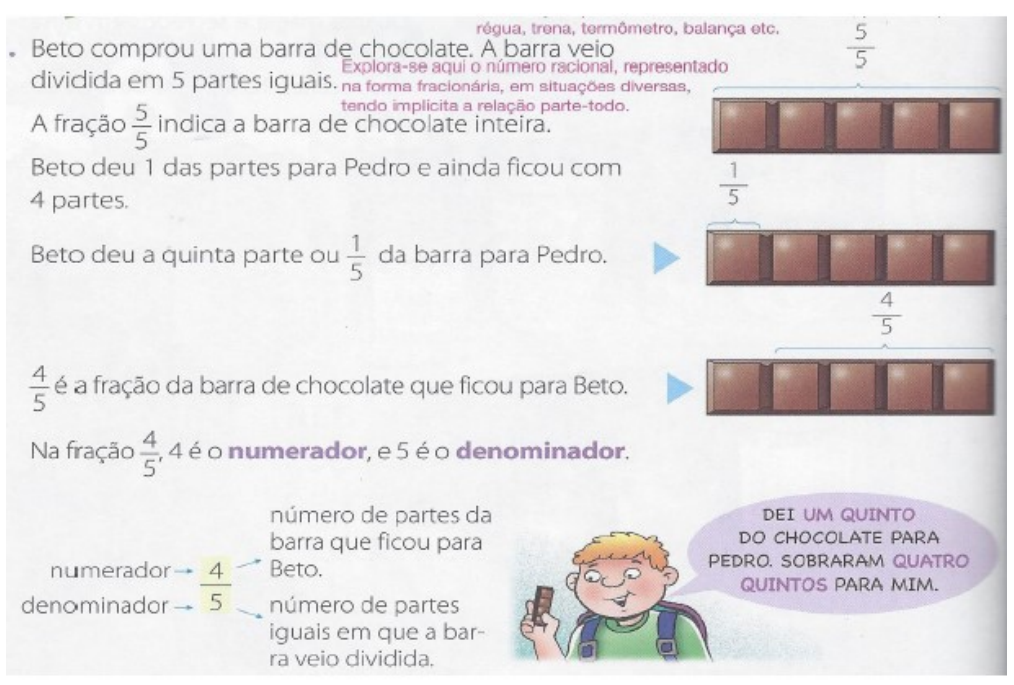

Figura 1 - A ideia de fração numérica Fonte: CENTURIÓN; SCALA; RODRIGUES, 2014, p.150

A relação parte-todo associada respectivamente aos conceitos de numerador e denominador é abordada nesta situação. O todo (denominador) é representado pelas cinco partes que compõem a barra de chocolate inteira e as partes (numerador) são os pedaços considerados da barra de chocolate. Percebemos que o todo está dividido em partes iguais, conforme informação contida no enunciado.

Esta situação corresponde a uma ação vivenciada por estudantes. Situações deste tipo, que refletem o cotidiano, podem ser mais atrativas e contribuírem para a participação e para o envolvimento dos estudantes, o que possibilitaria ao professor explorar as concepções prévias sobre frações, com intuito de identificar obstáculos de aprendizagem. A identificação de obstáculos é um momento importante para o professor, pois com base neles serão elaboradas práticas de ensino para tratá-los adequadamente, visando a aprendizagem.

Na sequência do livro, uma situação chama atenção. A situação-problema 2 (Figura 2) apresenta a divisão de uma representação triangular em três partes e remete à discussão acerca da maneira como a representação da forma geométrica (o todo) pode ser dividida.

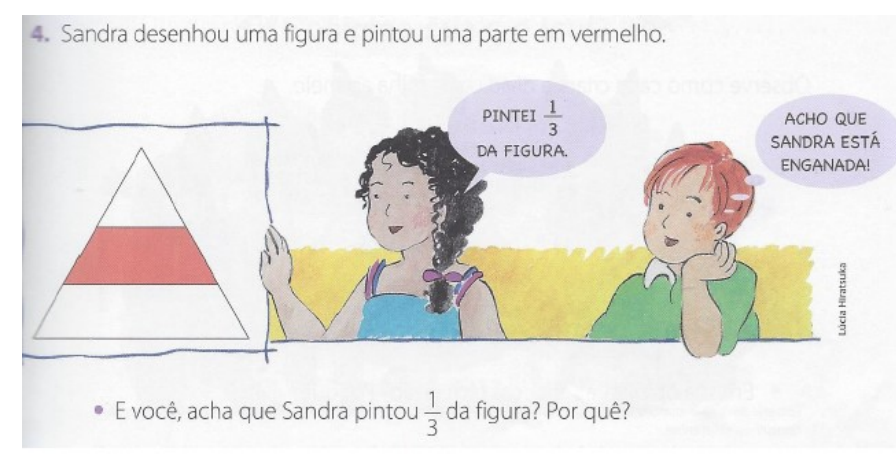

Figura 2 - Divisão do todo em partes

Fonte: CENTURIÓN; SCALA; RODRIGUES, 2014, p.151 
Esta situação contempla a divisão do todo em partes desiguais e permite refletir se qualquer divisão poderá corresponder a uma fração. Este é o momento que Astolfi $(1993 ; 1994 ; 1999)$ define como fissuração, onde o estudante é colocado em conflito sociocognitivo com a ideia de frações abordada na situação-problema 1, em que as partes possuíam o mesmo tamanho. Neste caso há uma contradição de informações, oriunda da comparação entre as situações-problema 1 e 2, que pode gerar no estudante a dúvida referente à maneira como o inteiro (o todo) deve ser dividido, para que sua representação corresponda a uma fração.

Para a etapa de superação do obstáculo de aprendizagem relacionado ao conceito de fração (relação parte-todo em que o todo deve ser dividido em partes iguais), o livro apresenta a situação-problema 3 (Figura 3), que além de ressaltar a necessidade da divisão do todo em partes iguais, possibilita as múltiplas representações de resposta. Situações deste tipo devem ser abordadas em sala de aula para que o estudante compreenda a diversidade de resultados para uma mesma situação, contrapondo ao princípio de verdade única, por vezes, presente na Matemática.
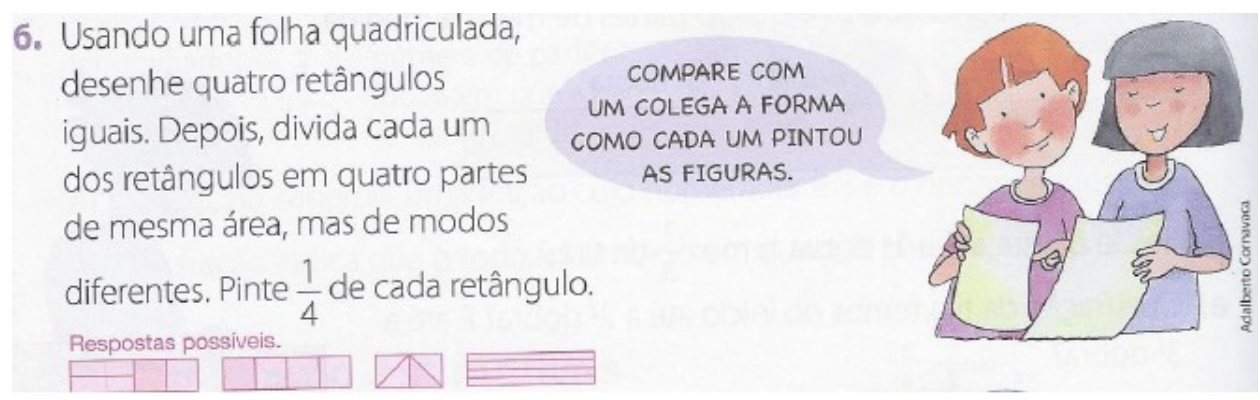

Figura 3 - Divisão do todo em partes iguais Fonte: CENTURIÓN; SCALA; RODRIGUES, 2014, p.152

Com vistas à apropriação do conceito de fração, no que tange à relação parte-todo, o professor poderá partir da situação-problema 3 e pedir aos estudantes que representem outras figuras geométricas.

Partindo das situações-problema selecionadas, no que tange à relação parte-todo, concluímos que a sequência didática apresentada está em consonância com a proposta de Astolfi $(1993 ; 1994 ; 1999)$, ou seja, são contemplados os momentos de identificação, de fissuração e de superação dos obstáculos de aprendizagem. Neste sentido, a sequência didática pode contribuir para que o estudante supere sua concepção prévia, construa o seu modelo explicativo embasado no conhecimento científico e promova a automatização do conhecimento, tão necessária em novas e diferentes situações em que ele vivenciará fora do espaço escolar. 
Até este momento, o livro apresenta situações que envolvem apenas o conceito de frações próprias, apesar de não utilizar esta nomenclatura. As frações próprias são representadas da forma $\mathrm{a} / \mathrm{b}$, onde o denominador $\mathrm{b}$ é um número natural maior que o numerador a (também número natural). Elas representam uma quantidade menor do que um inteiro.

O livro didático trata das operações de adição, subtração, multiplicação, divisão e simplificação, porém, envolvendo somente frações próprias. A ênfase neste tipo de situação pode contribuir para a formação de um novo obstáculo à aprendizagem, pois o estudante pode entender que uma fração sempre representa 'uma parte do todo'. Neste caso, o estudante adentraria numa zona de 'conforto' conceitual, criando certa comodidade intelectual, denominada por Astolfi $(1993 ; 1994)$ como obstáculo-facilidade, sem questionar a existência de possibilidades contrárias.

A inserção da situação-problema 4 (Figura 4) representa um novo momento de fissuração do obstáculo. O estudante pode confrontar a ideia de que toda fração é escrita da forma $a / b$, com $b$ maior que $a$, ou seja, a fração é sempre uma parte do todo. Como consequência, pode questionar se 5/4 representa uma fração e o que significa $5 / 4$, já que o denominador é um valor menor que o numerador.

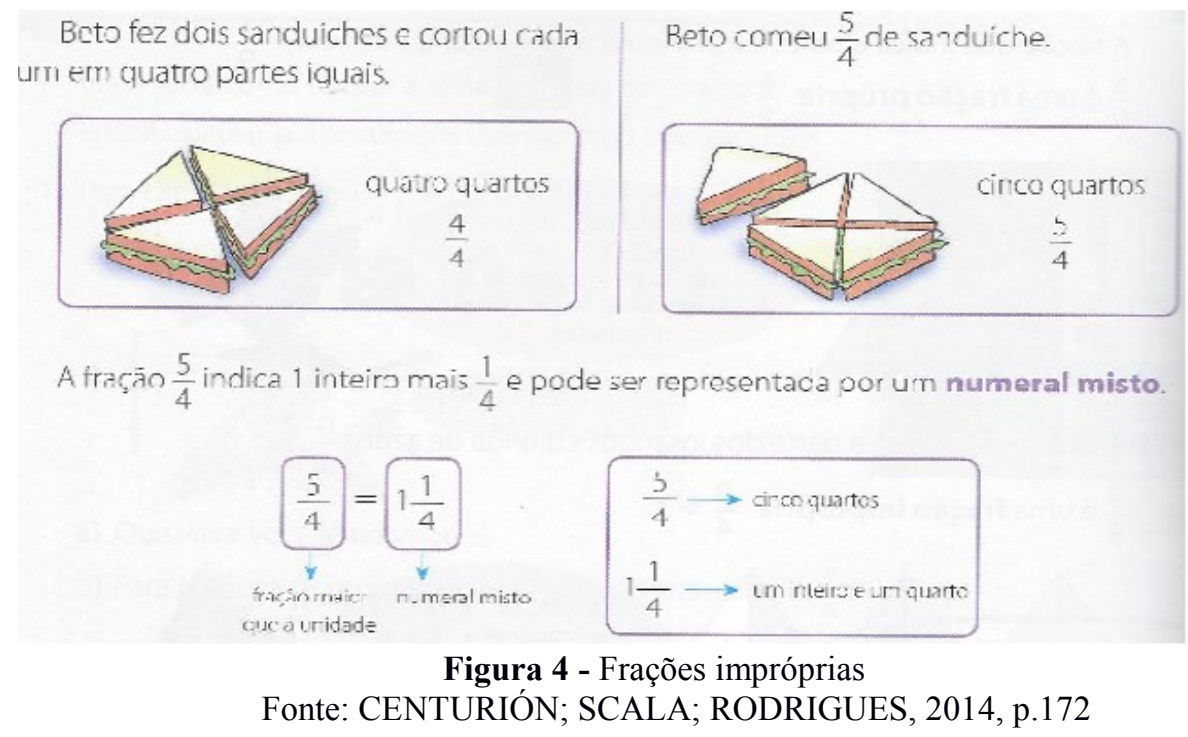

O livro não apresenta possibilidades de superação deste obstáculo à aprendizagem, pois se limita a poucas situações (mais especificamente três) que enfatizam as diferentes representações algébricas de frações, focando no algoritmo da conversão de frações em numeral misto e vice-versa. Sendo assim, o livro poderia contemplar um número maior de situaçõesproblema semelhantes a esta a fim de que o estudante clarifique as dúvidas emergidas da fissuração e compreenda o significado deste tipo de frações. 


\section{Considerações Finais}

Alicerçados na teoria de Astolfi (1999) analisamos e discutimos a apresentação do conceito de frações no livro didático, reconhecendo as etapas de identificação, fissuração e superação dos obstáculos de aprendizagem.

As três primeiras situações-problemas da sequência didática apresentada neste trabalho, permitiram localizar, fissurar e superar o primeiro obstáculo de aprendizagem referente ao conceito de fração, que indagava sobre a obrigatoriedade ou não do objeto inteiro (o todo) ser dividido em partes iguais. Num segundo momento, um novo obstáculo foi localizado, quando introduziu-se a ideia de que uma fração poderia representar um valor maior que a unidade, contrariando a ideia de que frações seriam 'partes do todo' e, portanto, menor que a unidade. Para este obstáculo, percebemos que o livro não possibilitou a superação, já que apresentou este tipo de frações de modo muito simplório, focado apenas na variação de sua representação escrita. Concluímos que a intenção dos autores tenha sido apenas mostrar que existe um novo tipo de fração, deixando para explorá-lo nos anos seguintes. Se este foi o propósito, julgamos coerente e sensata a postura dos autores, pois entendemos que estas frações poderiam ser apresentadas e aprofundadas no $6^{\circ}$ ano, sem prejuízo aos estudantes. Da mesma forma, percebemos que os autores não focaram na nomenclatura 'frações própria e impróprias', mas sim na compreensão conceitual.

Reforçamos a importância do professor na tríade didática (conhecimento-professoraluno), já que cabe a ele mediar o percurso de automatização do conhecimento científico utilizando-se como apoio, o livro didático. Esperamos ter contribuído para que estes profissionais possam identificar, fissurar e superar possíveis obstáculos que os estudantes apresentam durante o ensino de frações e assim, promover uma efetiva aprendizagem matemática.

\section{Referências}

ARTIGUE, M. Engenharia Didáctica. In: BRUN, Jean. Didáctica das Matemáticas. Lisboa: Instituto Piaget, 1996, p. 193-217.

ASTOLFI, J. P. Los obstáculos para el aprendizaje de conceptos en ciencias: la forma de franquearlos didácticamente. In: PALACIOS, C.; ANSOLEAGA, D. ; AJOS, A (org). Diez años de investigación innovación enseñanza de las ciencias. Madrid, CIDE, 1993, p.289-306.

El trabajo didáctico de los obstáculos, en el corazón de los aprendizajes científicos.

Enseñanza de las Ciencias, n. 2, v.12, 1994, p. 206-216. 
. El tratamiento didáctico de los obstáculos epistemológicos. Revista Educacion y

Pedagogia, Medellin, n. 25, septiembre/diciembre,1999, p.149-172.

BARTZ DE SÁ, F. Aprendizagem de frações no ensino fundamental. 2011. 99 f. TCC (Graduação) - Curso de Matemática, Departamento de Matemática Pura e Aplicada, Universidade Federal do Rio Grande do Sul, Porto Alegre, 2011. Disponível em:

$<$ http://www.lume.ufrgs.br/bitstream/handle/10183/31633/000784031.pdf >. Acesso em: 01 fev. 2016.

BEZERRA, R. C.; BONDEZAN, A. N. O ensino da Matemática no Curso de Pedagogia/Parfor: Refletindo a Formação de professores. Trilhas Pedagógicas, Pirassununga, v. 5, n. 5, p.122-133, ago. 2015.

BRASIL. Lei de Diretrizes e Bases da Educação Nacional, n. 9394, de 20 de dezembro de 1996.

BRASIL. Secretária de Educação Fundamental. Parâmetros Curriculares Nacionais: matemática. Brasília: MEC; SEF, 1997.

BRASIL. Resolução no 2, de 01 de julho de 2015a. Diretrizes Curriculares Nacionais Para Educação Básica: Define as Diretrizes Curriculares Nacionais para a formação inicial em nível superior (cursos de licenciatura, cursos de formação pedagógica para graduados e cursos de segunda licenciatura) e para a formação continuada. Brasília, DF.

BRASIL. Guia de livros didáticos: PNLD 2016: Alfabetização Matemática e Matemática: ensino fundamental anos iniciais. Brasília: Ministério da Educação, Secretária de Educação Básica, 2015b.

BRASIL. Secretária de Educação Básica. Base Nacional Curricular Comum: educação é a base. Brasília: MEC; SEB, 2017.

BROSSEAU, G. Fundamentos e Métodos da Didáctica da Matemática. In: BRUN, Jean. Didáctica das Matemáticas. Lisboa: Instituto Piaget. Horizontes Pedagógicos, 1996, p. 35-113.

CENTURIÓN, M. R.; SCALA, J. L.; RODRIGUES, A. B. Coleção porta aberta: matemática, ensino fundamental, anos iniciais. São Paulo: FTD, 2014.

DANTE, L. R. Livro Didático de Matemática: uso ou abuso? Em Aberto, Brasília, ano 16, n.69, 1996.

D'AMORE, B. Elementos de Didática da Matemática. São Paulo: Editora Livraria da Física, 2007.

LOPES, A. J. O que Nossos Alunos Podem Estar Deixando de Aprender sobre Frações, quando Tentamos lhes Ensinar Frações. Bolema, Rio Claro, v. 21, n. 31, p.1-22, 2008.

MONTEIRO, A. B; GROENEALD, C. L. Dificuldades na Aprendizagem de Frações: Reflexões a partir de uma Experiência Utilizando Testes Adaptativos. Alexandria: Revista de Educação em Ciência e Tecnologia, Florianópolis/SC, v.7, n.2, p.103-135, nov. 2014.

NOVAES, B. W. D.; VENITES, F. O tema Frações na Revista de Ensino (1951 A 1963) e seus entrelaçamentos com o presente. XII Seminário Temático Saberes Elementares Matemáticos do Ensino Primário (1890 - 1970): o que dizem as revistas pedagógicas? (1890 - 1970). Escola de Educação e Humanidades, PUC/PR, Curitiba: PR. Disponível em:

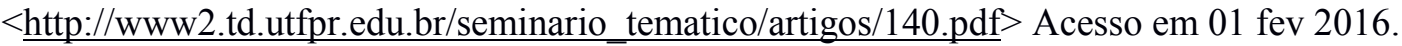

OLIVEIRA, M. R. N. S. (org.). Didática: Ruptura, compromisso e pesquisa. $2^{\mathrm{a}}$ ed. Campinas/SP: Papirus, 1995. 
OLIVEIRA, A. T. C. C. Saberes e práticas de formadores de professores que vão ensinar matemática nos anos iniciais. 2007. 227 f. Tese (Doutorado) - Curso de Programa de Pós-graduação em Educação, Departamento de Educação, Pontifícia Universidade Católica do Rio de Janeiro, Rio de Janeiro, 2007.

SANTA CATARINA. Secretaria de Estado da Educação. Proposta curricular de Santa Catarina: Formação Integral na educação Básica. Santa Catarina, SED, 2014.

\section{Agradecimentos}

Apoio financeiro Coordenação de Aperfeiçoamento de Pessoal de Nível Superior Capes

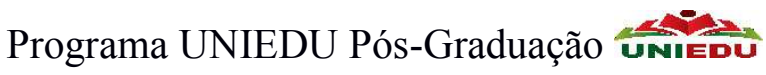

